\title{
Un documento de don Hernando Colón (1536)
}

\section{One document about don Ferdinand Columbus (1536)}

\author{
Pedro Andrés PORRAS ARBOLEDAS \\ Catedrático acreditado de Historia del Derecho \\ Departamento de Historia del Derecho \\ Instituto de Metodología e Historia de la Ciencia Jurídica \\ Facultad de Derecho. Universidad Complutense de Madrid \\ pporras@der.ucm.es
}

Recibido: 7 de septiembre de 2015

Aceptado: 9 de octubre de 2015

\section{RESUMEN}

A comienzos de 1536 don Hernando Colón, hijo ilegítimo del Almirante, compareció ante el Consejo de Órdenes Militares para reclamar a su concuñado, don García Álvarez de Toledo, comendador de Monreal, el millón de mrs. que su padre, don Fernando Álvarez de Toledo, había prometido a otra hija suya, doña María, como dote para su matrimonio con don Diego Colón, virrey de las Indias, hermanastro de don Hernando. Este había adelantado el total de la dote a su cuñada y exigía al hermano de ésta el abono de la misma, al no haberlo hecho don Fernando a su debido tiempo.

PALABRAS CLAVE: Cristóbal Colón, Almirante mayor de la Mar Océana, don Diego Colón, don Hernando Colón, doña María Álvarez de Toledo.

\begin{abstract}
At the beginning of 1536 don Ferdinand Columbus, the illegitimate child of the Admiral, appeared before the Council of Military Orders to claim from his brother-in-law's brother, don García Álvarez of Toledo, commander of Monreal, the million of mrs. that his father, don Fernando Álvarez of Toledo, had promi-sed to his daughter, doña María, as the dowry for her marriage with don Diego Columbus, viceroy of the Indies, step-brother of don Ferdinand. This last had advanced the totality of the dowry to his sister-in-law and was claiming its reimbursement from her brother, because don Ferdinand de Toledo had not cancelled it duly.
\end{abstract}

KEYWORDS: Christopher Columbus, major Admiral of the Ocean Sea, don Diego Columbus, don Ferdinand Columbus, doña María Álvarez of Toledo.

\section{RÉSUMÉ}

Au début de 1536 don Fernand Colomb, fils illégitime de l'Amiral, a comparu devant le Conseil des Ordres Militaires pour réclamer à son beau-frère, don García Álvarez de Tolède, commandeur de Monreal, le million de mrs. que son père, don Fernand Álvarez de Tolède, avait promis à sa fille, doña Marie, comme dot pour son mariage avec don Diego Colomb, viceroy des Indes, un demi-frère de don Fernand. Celui-ci avait avancé la totalité de la dot à sa belle-soeur et exigeait maintenant au frère de celle-ci l'abonnement de la même, puis qu'il n'avait été pas fait par don Fernand de Tolède à son tour.

MOTS CLÉ : Christophe Colomb, grand Amiral de la Mer Océanique, don Diego Colomb, don Fernand Colomb, doña Marie Álvarez de Tolède. 
No es muy habitual encontrar en archivo documentos nuevos sobre personajes históricos relevantes o relacionados con otros actores de esa categoría; don Hernando Colón, hijo bastardo del Almirante don Cristóbal Colón, brilla tanto por esa relación familiar con el descubridor de América, como con luz propia, habida cuenta de su vida de viajero y bibliófilo, en los albores de los tiempos modernos.

La biografía de don Hernando es bien conocida y ha merecido desde antiguo que distintos autores se ocupen de ella. En este breve estudio tan sólo quiero glosar un documento recientemente hallado entre los miles de provisiones reales atesoradas en el Registro General del Sello de la Orden de Santiago del Archivo Histórico de Toledo (AHN, Órdenes Militares).

Se trata de un mandamiento de pago librado por el Consejo de Órdenes Militares a don García Álvarez de Toledo, comendador de Monreal, para que en breve plazo abonase a don Hernando una deuda contraída previamente. Entre las provisiones a que me vengo refiriendo existen dos tipos documentales que podemos denominar «mandamientos de pago»: una primera, que es la que debe recibir dicha denominación con más propiedad; es decir, las órdenes dadas por un superior a un inferior para que haga efectivo un pago a un tercero, tal como haría un empresario a su administrador para que abonase los salarios a sus empleados.

Sin embargo, en el presente caso estamos en presencia de un segundo tipo, en el que un acreedor acude ante la autoridad judicial para que inste a su deudor a hacerle efectivo el pago de una deuda contraída en virtud de una obligación que llevaba o no aparejada ejecución. Si no la llevaba aparejada, el tribunal citaba a las partes a juicio contradictorio para que se estableciese la existencia o no de la deuda reclamada. Si la llevaba aparejada, lo habitual era que el juez ordenase al deudor que en breve plazo pagase al acreedor la deuda, eso sí, siempre se le concedía la posibilidad de que en un plazo, superior al primeramente concedido para pagar, presentase las excepciones oportunas que enervasen la obligación alegada. Esto es, que se hubiese satisfecho ya el pago, que se hubiera producido novación mediante nueva obligación, etc.

En el presente caso estamos, pues, en presencia de uno de estos últimos mandamientos de pago, en los que vemos intervenir a dos familias entrelazadas por el matrimonio. De un lado, tenemos a don Fernando Álvarez de Toledo, personaje de relevancia en la Orden de Santiago, donde había llegado a ser comendador mayor de León; don Fernando ya había fallecido al tiempo de la emisión del documento en cuestión († 1532). Dos de sus hijos son los reflejados en nuestro texto: don García Álvarez de Toledo, que era comendador de Monreal en 1536, además de sucesor en el presunto mayorazgo de su padre, y doña María Álvarez de Toledo, viuda de don Diego Colón, hijo legítimo del Almirante y, por tanto, virreina consorte de las Indias. Del lado de la familia Colón, contamos con la presencia de su hijo legítimo don 
Diego, su sucesor en dicho virreinato y almirantazgo, y el ilegítimo don Hernando. El ligamen entre ambas familias era, pues, el matrimonio entre don Diego y doña María. Don Diego ya había fallecido en el momento de la expedición del documento. ${ }^{1}$

Don Fernando Álvarez de Toledo y Enríquez, era hijo segundón del primer duque de Alba, don García Álvarez de Toledo, y llegó a constituir un señorío en torno a la villa salmanticense de Villoria. De sus hijos, doña María, como vemos, emparentó con la familia Colón, falleciendo en la isla de Santo Domingo en 1549, y don García heredaría de don Fernando el señorío de Villoria.

Precisamente, la causa del documento viene dada por el pago de la dote recibida por doña María de manos de su difunto padre o, para ser más preciso, la promesa de dote realizada por don Fernando cuando su hija se desposó con don Diego. Según parece, don Fernando nunca llegó a hacer efectivo el pago del millón de maravedíes - cantidad ciertamente importante, aunque no exorbitante - prometidos a su yerno, don Diego. Al parecer, doña María había cedido a su cuñado don Hernando los documentos dotales y un poder en causa propia para que éste cobrase dicha cantidad; es evidente que don Hernando había adelantado dicha cantidad a su cuñada y ésta le había cedido sus derechos para el abono de la dote. Estos documentos fueron presentados por don Hernando ante el tribunal competente, que era el Consejo de Órdenes, por cuanto el obligado al pago, a quien se reclamaba el cuento de mrs., era don García, que tenía fuero privilegiado como caballero de la Orden de Santiago.

Así pues, don Hernando acudió ante el Consejo de Órdenes y presentó la escritura dotal y el poder en causa propia - esto es, un poder para cobrar en nombre de doña María, que le permitía quedarse con el dinero cobrado- que había recibido de manos de doña María contra el pago del millón de mrs. El Consejo, como solía ser habitual en estos casos, se saltó el tramo probatorio, por cuanto los documentos hacían fe respecto a la obligación contraída por don Fernando y por su sucesor en los bienes de la casa, don García, con su hija doña María.

La resolución del Consejo no presentaba dudas, pues el documento era de los que llevaban aparejada ejecución — cláusula guarentigia, como era denominada en los documentos de la época—, de modo que ordenó el pago en 9 días a don García, so

\footnotetext{
${ }^{1}$ Un hijo de don Diego y doña María, también llamado don Diego Colón, obtendría el hábito santiaguista por provisión librada en Madrid, el 9 de marzo de 1535, una semana después de que el Emperador partiese para Italia; por esos días lo recibieron también Carlos de Briseu, Diego de Rojas, hijo del marqués de Denia, don Francés de Lodosa, señor de Sarria, Juan Dávalos, hijo de Rodrigo Dávalos, y don Íñigo de Tovar, hijo de don Juan de Tovar, marqués de Berlanga. Decía el asiento dedicado a don Diego:

Este dicho día se despachó otro ábito de don Diego Colón, hijo de don Diego Colón, almyrante e visorrey de las Yndias del mar océano, difunto, e yva dirigido para que le armasen cavallero a don Juan de Çúñiga, comendador mayor de Castilla, y para que le diesen el ábito el licenciado Artiaga, fleyre de la Orden, y pagó de la provisyón e ynformación quatorze reales.

Se conservan estos datos en una hoja suelta dentro del libro-registro de las provisiones emitidas y derechos cobrados por ello del período 1531-1535, único de la época que ha llegado hasta nosotros (AHT, expte. 51.986).
} 
pena de, en caso contrario, ser ejecutado en sus bienes por el importe de la deuda, más gastos y costas. No obstante, si tuviera alguna excepción que alegar a su favor para no pagar, se le concedía un total de 20 días para hacerlo.

Parece ser que el segundo señor de Villoria optó por no darse por enterado de la petición de don Hernando y del consecuente mandamiento del Consejo; el ejecutante siguió fundamentando su petición, así, el 30 de septiembre de ese mismo año 1536, el Consejo emitió una requisitoria a todas las justicias del Reino, a petición de don Hernando Colón, que necesitaba conseguir una escritura otorgada por don García antes de tomar posesión de la villa de Villoria, en que constaba cómo éste había aceptado la herencia del comendador mayor, obligándose a satisfacer todas sus deudas, documento que se había otorgado ante el escribano público ejerciente en Villoria. ${ }^{2}$ Nueve días más tarde, don Hernando ganó otra requisitoria, dirigida especialmente a las justicias de Valladolid, donde estaba la Corte, para que doña Isabel Pimentel, viuda de don Fernando Álvarez de Toledo, aportase ese documento y, citada la parte de don García, diesen traslado del mismo al peticionario, don Hernando. ${ }^{3}$

Finalmente, se dictó por el Consejo, en rebeldía del ejecutado, una sentencia (Valladolid, 07/11/1536), por la que se le condenó al abono de la deuda en 9 días, más las costas del proceso. Cuatro días más tarde, Juan de Álava, procurador de don García, suplicó ante las personas reales, apelación que le fue otorgada, cometiéndose su determinación a los Lcdos. Hernando Girón y Pedro Girón, del Consejo Real, y al Lcdo. Sarmiento y al Dr. Anaya, del Consejo de Órdenes. ${ }^{4}$ Desgraciadamente, no se conserva la sentencia definitiva ni el texto completo de la ejecutoria, de modo que desconocemos el final del proceso.

Tan sólo en mayo de 1539 nos consta una misteriosa anotación del secretario Guerrero, al dorso de una provisión reutilizada, por la que se dice que se había concedido a don Hernando una carta compulsoria. ${ }^{5} \mathrm{O}$ corresponde a una fecha muy anterior, durante la celebración del proceso que comentamos, o se trata de un caso diferente.

\footnotetext{
${ }^{2}$ AHT, expte. 78.237.

${ }^{3}$ AHT, expte. 78.238 .

${ }^{4}$ AHT, expte. 78.244. Se trata de un fragmento de la ejecutoria, conservada entre las provisiones de abril de 1537. La executoria de juezes probablemente fue librada en octubre de ese año, como consta en una anotación del secretario del Consejo de ese mes (AHT, expte. 78.250).

${ }^{5}$ AHT, expte. 78.269.
} 


\section{APÉNDICE DOCUMENTAL}

\section{6/01/18. Madrid}

Mandamiento de pago a don García de Toledo, comendador de Monreal, a petición de Sebastián Rodríguez, procurador de don Hernando Colón, vecino de Sevilla, como cesionario de doña María de Toledo, virreina de las Indias, viuda de don Diego Colón, virrey de las Indias, que expuso que cuando doña María casó con don Diego, don Fernando de Toledo, comendador mayor que fue de León, ya difunto, padre de ella y de don García, le dio en dote y casamiento por bienes dotales un cuento de mrs. pagados a cierto plazo, según escritura de obligación y promesa de dote que presentó; fallecido don Diego, doña María traspasó a don Hernando el derecho a esa cantidad, en pago de una deuda que con él tenía, según escritura de cesión y poder en causa propia; fallecido el padre de ambos, don Fernando de Toledo, le habia dejado por hijo y heredero de gran cantidad de bienes, vasallos y rentas, que poseía al haber aceptado la herencia, razón por la que estaba obligado a satisfacer aquella deuda. Reclamada, no la había querido pagar.

Orden de pagar en 9 días tras ser notificado o de presentar excepciones en otros 20 días.

Archivo Histórico Nacional, Órdenes Militares, Archivo Histórico de Toledo, expte. 78.229.

A don García de Toledo, comendador de Monreal, que pague a don Hernando Colón un quento de mrs. o parezca en el Consejo. Don Hernando Colón. Madrid, henero de .MDXXXVI. años.

Don Carlos, etc. A vos, don García de Toledo, comendador de Monreal. Salud e gracia. Sepades que Sebastián Rodrigues, en nonbre e como procurador de don Fernando Colón, vezino de la cibdad de Sevilla, como cesyonario de doña María de Toledo, virreyna de las Yndias, muger que fue de don Diego Colón, ya difunto, virrey de las dichas Yndias, me fizo relación por su petición que en el mi Consejo de la dicha Orden presentó, diziendo que al tienpo que la dicha doña María de Toledo se ovo de casar con el dicho don Diego Colón, diz que don Fernando de Toledo, comendador mayor que fue de León, ya difunto, vuestro padre e suyo, le mandó en dote e casamiento e por sus bienes dotales e caudal un quento de mrs., pagados a cierto plazo pasado, según parescía por cierta escriptura de obligación e prometimiento de dote sygnada, de que hizo presentación, e que después que falleció el dicho Diego Colón la dicha doña María de Toledo, su muger, tenyendo por cobrar e recibir el dicho quento de mrs. cedió e traspasó e remitió el derecho que tenya para pedillo e cobrallo en el dicho don Fernando de Colón por razón de cierta deuda que le devía y sus derechos e aciones, como parescía asy mysmo por otra escritura de cesyón e poder en causa propia, de que fizo presentacion, e que, al tienpo del fallecimiento del dicho comendador mayor de León, vuestro padre, os dexó por fijo y heredero de muchos bienes e vasallos e rentas e que vos como tal fijo y heredero acebtastes los dichos bienes y herencia y los tenéys e poseéys en mucha cantidad y que por razón dello soys tenudo e obligado de dar e pagar al dicho don Fernando Colón, como cesonario de la dicha doña María de Toledo e de sus fijos, el dicho quento de mrs. e que, puesto que por su parte avéys sydo pedido e requerido que se los deys e paguéys, como soys obligado, diz que no lo avéys querido ny queréys fazer, suplicándome os mandase que le diésedes e pagásedes luego el dicho quento de mrs. e que, sy necysario fuese, por sentencia pronunciada en el dicho my Consejo lo mandase sentenciar e pronunciar e declarar e fazerle sobrello cunplimiento de justicia, como la my merced fuese.

Y en el dicho my Consejo fue acordado que devía mandar dar esta my carta en la dicha razón e yo tóvelo por bien, porque vos mando que del día que os fuere notificada en vuestra persona, sy pudierdes ser avido, sy no ante las puertas de las casas de vuestra más continua morada diziéndolo, haziéndolo saber a vuestra muger o hijos, sy los avedes, o a vuestros criados o vezinos más cercanos, por manera que pueda venyr a vuestra noticia e no pretendáys ynorancia fasta nueve días primeros siguientes deys y paguéys al dicho don Hernando Colón o a quyen su poder para ello oviere el dicho quento de mrs. de suso declarado, pero, si alguna razón legítima tenéys para que no gelos deváys dar ny pagar, paresced a la alegar e mostrar ante los del dicho my Consejo por vos o por vuestro procurador bastante byen ystruto 
e ynformado cerca de lo susodicho desd'el día qu'esta dicha carta os fuere notificada, como dicho es, fasta otros veynte días primeros syguientes que vos doy e asyno por todos plazos e término perentorio e, sy parescierdes en el dicho my Consejo, vos oyrán e vos será guardada vuestra justicia, en otra manera vuestra ausencia e rebeldía, no enbargante aviéndola por presencia, procederán en la dicha causa, según e como hallaren por derecho, syn vos más citar ny llamar, que para lo que dicho es para todos los otros autos e mérytos de la dicha causa con sentencia difinitiva ynclusyve e tasación de costas, sy las oviere, vos cito y llamo perentoriamente por esta mi carta, por la qual mando, so pena de la my merced e de diez mill mrs. para la my cámara, a qualquier escrivano público que para esto fuere llamado que os lea e notifique esta dicha my carta e dé testimonio dello para que yo sepa en cómo se cunple my mandado.

Dada en la villa de Madrid, a .XVIII. días de henero de .MDXXXVI. años.

El conde don Garci Manrique. Licenciatus Luxan. Licenciatus Sarmiento. Licenciado de Álaba. Secretario, Guerrero. 